\title{
SALURAN DAN MARGIN PEMASARAN DURIAN HASIL AGROFORESTRI DI DESA SIDODADI
}

\author{
Channel And Margin Marketing Of Durian Agroforestri Results In Sidodadi Village
}

\author{
Ari Yudha Prasetya*, Rommy Qurniati, Susni Herwanti \\ Jurusan Kehutanan, Fakultas Pertanian, Universitas Lampung. \\ JI. Sumantri Brojonegoro 1, Bandar Lampung, 35145, Lampung, Indonesia \\ *Email: ariyudhaprasetya96@gmail.com
}

Direvisi : 16/10/2019, Diterbitkan 02/03/2020

\begin{abstract}
Durian is a plant that has high production potential planted by farmers in Sidodadi Village with agroforestry patterns. This production potential can provide benefits for farmers if they are able to be marketed efficiently. The purpose of this study was to analyze the channels and margins of durian marketing in Sidodadi Village, Teluk Pandan District, Pesawaran District, Lampung Province. The study was conducted in January 2019 with the object of research by farmers and durian marketing institutions in Sidodadi Village. Analysis was carried out qualitatively to assess marketing channels and quantitatively to calculate marketing margins. The results showed that marketing of durian in Sidodadi Village consisted of 3 marketing channels and led to the oligopsonistic market structure. The uneven value of marketing margins, profits, and farmer shares has caused the marketing system to be inefficient.
\end{abstract}

Keywords; Marketing costs; Marketing efficiency; Marketing margin; Farmer share.

\begin{abstract}
ABSTRAK
Durian merupakan tanaman yang memiliki potensi produksi yang tinggi yang ditanam oleh petani di Desa Sidodadi dengan pola agroforestri. Potensi produksi ini dapat memberikan keuntungan bagi petani jika mampu dipasarkan dengan efisien. Tujuan penelitian ini adalah menganalisis saluran dan margin pemasaran durian di Desa Sidodadi Kecamaan Teluk Pandan kabupaten Pesawaran Provinsi Lampung. Penelitian dilakukan pada bulan Januari 2019 dengan objek penelitian petani dan lembaga pemasaran durian di Desa Sidodadi. Analisis dilakukan secara kualitatif untuk mengkaji saluran pemasaran dan kuantitatif untuk menghitung margin pemasaran. Hasil penelitian menunjukkan bahwa pemasaran durian di Desa Sidodadi terdiri dari 3 saluran pemasaran dan mengarah pada bentuk pasar oligopsoni. Nilai margin pemasaran, keuntungan, dan farmer share yang belum merata menyebabkan sistem pemasaran belum efisien.
\end{abstract}

Kata kunci; Efisiensi pemasaran; Biaya pemasaran; Margin pemasaran; Farmer share. 


\section{PENDAHULUAN}

Keberadaan hutan sangat penting bagi makhluk hidup, kebermanfaatannya dapat dirasakan baik secara langsung atau tidak langsung. Kebermanfaatan hutan perlu dijaga melalui pembangunan dan pengelolaan yang baik untuk mewujudkan pengelolaan hutan lestari guna mendukung kehidupan dan kesejahteraan masyarakat (Syofiandi et al., 2016). Salah satu cara mewujudkan pengelolaan hutan lestari dapat dilakukan dengan sistem agroforestri. Agroforestri merupakan bentuk penggunaan lahan secara multi tajuk dengan kombinasi pepohonan tanaman semusim atau ternak dalam satu lahan (Olivi et al., 2015). Winarni et al., 2016 dalam penelitiannya menyatakan hal yang serupa bahwa agroforestri merupakan sistem kebun campuran. Agroforestri memberikan kontribusi melalui perkebunan, pertanian, dan peternakan (Syofiandi et al. 2016).

Salah satu penerapan agroforestri dilakukan oleh masyarakat Desa Sidodadi Kecamatan Teluk Pandan Kabupaten Pesawaran pada lahan Taman Hutan Raya Wan Abdul Rachman (Tahura WAR). Kristin et al., 2018 menjelaskan bahwa masyarakat di Desa Sidodadi sudah lama melakukan kegiatan interaksi dalam pemanfaatan kawasan Tahura WAR dan ketergantungannya terhadap hutan masih tinggi (Qurniati et al., 2017). Kegiatan pemanfaatan hutan yang dilakukan masyarakat di Desa Sidodadi berupa penanaman, pemeliharaan, dan pemanenan (Hanum et al., 2018). Penelitian Wanderi et al. (2018) menunjukkan bahwasanya terdapat 7 komposisi tanaman agroforestri di Desa Sidodadi yang didalamnya ditanami tanaman Multi Purpose Tree Species (MPTS). Hasil MPTS yang ditanam pada lahan agroforestri menjadi sumber pendapatan yang dapat digunakan oleh masyarakat dalam mendukung kebutuhan ekonominya. Durian merupakan tanaman MPTS yang paling banyak ditanam masyarakat di lahan Tahura WAR (Wanderi et al. 2018) dan memberikan kontribusi yang tinggi pada pendapatan petani (Kholifah et al. 2017). Data pada Unit Pelaksana Teknis Daerah Tahura WAR (2017) menunjukkan bahwa potensi buah durian di Tahura WAR mencapai 387.139 gandeng/tahun. Potensi yang tinggi dari durian dapat menjadi sumber ekonomi bagi petaninya jika durian dapat dipasarkan dengan efisien mengingat salah satu kelemahan durian adalah memiliki sifat yang mudah rusak sehingga harus segera dipasarkan. Efisien atau tidaknya suatu pemasaran dapat dianalisa dari bagaimana saluran pemasaran dan margin pemasaran pada masing-masing saluran yang dilalui oleh durian tersebut. Untuk itu perlu dilakukan penelitian yang bertujuan untuk menganalisis saluran dan margin pemasaran durian di Desa Sidodadi Kecamatan Teluk Pandan Kabupaten Pesawaran Provinsi Lampung.

\section{METODE}

Penelitian ini dilaksanakan bulan Januari 2019 yang berlokasi di Dusun 3 dan Dusun 4 Desa Sidodadi Kecamatan Teluk Pandan Kabupaten Pesawaran yang berbatasan dengan Tahura WAR. Peta lokasi penelitian Dusun 3 dan 4 Desa Sidodadi disajikan pada Gambar 1. 

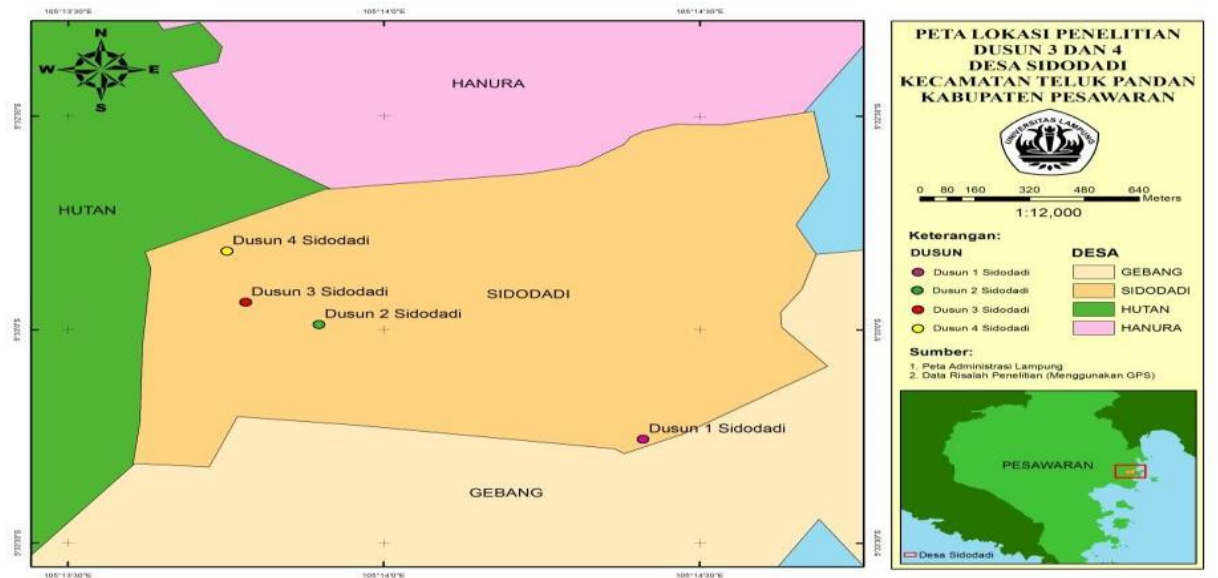

Gambar 1. Peta lokasi penelitian.

Figure 1. Map of research location.

Sumber: Kristin et al. (2018)

Objek penelitian ini adalah petani dan lembaga pemasaran durian di Desa Sidodadi. Penentuan jumlah sampel untuk responden petani dilakukan dengan penarikan sampel secara cluster sampling dalam menentukan jumlah petani durian, sedangkan untuk lembaga pemasaran duriandi belum diketahui jumlahnya secara pasti, sehingga responden lembaga pemasaran akan diambil secara snowball sampling. Alat yang digunakan dalam penelitian ini meliputi kuisioner, alat tulis, kamera, dan laptop.

Data yang diambil dalam penelitian ini terbagi atas data primer dan sekunder. Data primer adalah data yang diperoleh secara langsung di lapangan dengan melakukan metode wawancara secara terstruktur dengan menggunakan kuisioner kepada petani dan lembaga pemasaran durian. Data yang dibutuhkan dalam penelitian ini adalah (a) data saluran pemasaran; (b) data margin dan keuntungan pemasaran. Data Sekunder adalah data yang diperoleh dari adanya studi literatur dalam jurnal dan buku terkait penelitian. Data yang dibutuhkan dalam penelitian ini adalah (a) data kondisi umum Tahura Wan Abdul Rachman; (b) data produksi komoditas durian di Provinsi Lampung.

Analisis data dilakukan secara kualitatif dan kuantitatif untuk menjawab tujuan penelitian. Analisis kualitatif dilakukan pada saluran pemasaran meliputi komponen saluran pemasaran yang dilalui durian, lembaga-lembaga yang terlibat dalam pemasaran durian, fungsi-fungsi yang dilakukan lembaga pemasaran, sistem penentuan harga, dan jenis-jenis produk yang dipasarkan. Analisis kuantitatif digunakan pada margin pemasaran beserta penyebarannya, meliputi biaya dan keuntungan pemasaran serta farmer share. Perhitungan margin dilakukan dengan konsep pengukuran sebagai berikut.

1. Margin pemasaran merupakan nilai selisih antara harga beli dengan harga jual durian pada lembaga pemasaran dengan satuan rupiah.

2. Biaya pemasaran merupakan jumlah biaya-biaya yang harus dikeluarkan setiap lembaga pemasaran dengan satuan rupiah.

3. Margin keuntungan merupakan nilai selisih antara margin keuntungan dengan total dari biaya pemasaran dengan satuan rupiah.

4. Farmer share merupakan persentase nilai dari perbandingan harga penjualan petani dengan harga beli pada tingkat konsumen akhir. 


\section{HASIL dan PEMBAHASAN}

\section{Saluran Pemasaran}

Pemasaran durian hasil agroforestri di Desa Sidodadi dalam alur pendistribusiannya melibatkan petani, pengumpul, dan pengecer untuk sampai pada konsumen akhir. Proses alur pendistribusian yang bergerak dari petani sampai dengan konsumen akhir disebut dengan saluran pemasaran (Suminartika dan Djuanalia, 2017). Saluran pemasaran durian yang ada di Desa Sidodadi disajikan pada Gambar 2.

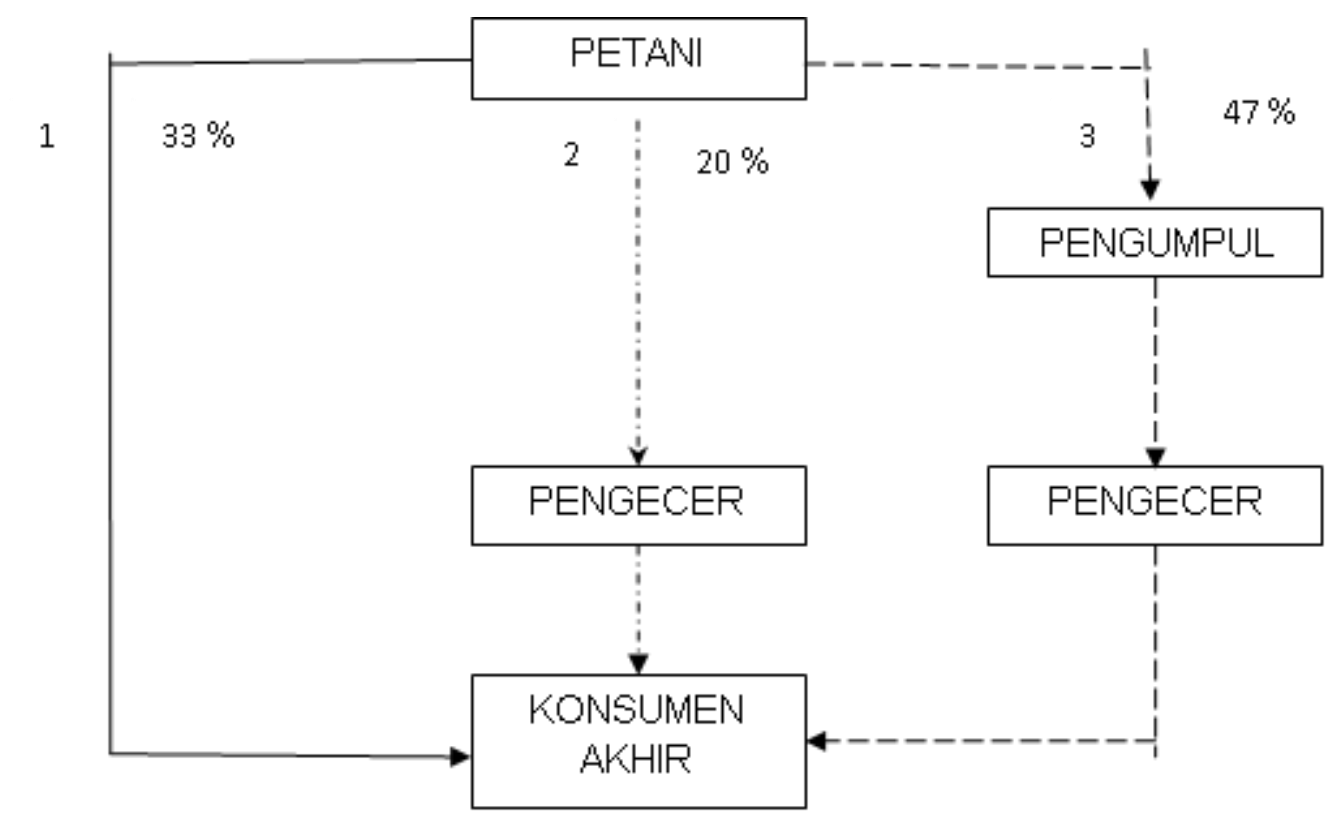

Gambar 2. Saluran pemasaran durian di Desa Sidodadi Figure 2. Durian marketing channel in Sidodadi Village

Saluran pemasaran yang ada di Desa Sidodadi terdiri dari 3 saluran pemasaran. Saluran 1 terdiri dari petani yang langsung menjual durian kepada konsumen akhir dan digunakan sebanyak 5 orang (33\%). Saluran 2 terdiri dari petani yang langsung menjual durian ke pengecer dan didistribusikan ke konsumen akhir, saluran 2 digunakan sebanyak 3 orang (20\%). Saluran 3 terdiri dari petani yang menjual durian ke pengumpul, lalu pengecer dan terakhir didistribusikan ke konsumen akhir. Saluran ini digunakan sebanyak 7 orang (47\%). Keterlibatan lembaga pemasaran seperti pengumpul dan pengecer di dalam saluran pemasaran adalah menjalankan fungsi-fungsi pemasaran. Fungsi-fungsi pemasaran yang dilakukan lembaga pemasaran meliputi fungsi fisik, pertukaran, dan fasilitas (Sabrina et al., 2013). Fungsi pemasaran yang dilakukan oleh pengumpul dan pengecer di Desa Sidodadi dapat dilihat pada Tabel 1.

Lembaga pemasaran di Desa Sidodadi yang terdiri dari pengumpul dan pengecer melakukan fungsi pertukaran, fisik, dan fasilitas. Fungsi pertukaran yang dilakukan oleh pengumpul dan pengecer ditunjukan dengan adanya pembelian durian dari petani. Pengumpul dan pengecer membeli durian dari petani dalam menyediakan durian untuk dijual. Hal ini sejalan dengan 
Annisa et al. (2018) yang menjelaskan bahwa lembaga pemasaran akan membeli produk dari petani, lalu akan dijual kembali dipasaran.

Tabel 1. Fungsi Pemasaran

Table 1. Marketing Function

\begin{tabular}{|c|c|c|c|c|c|c|}
\hline \multirow{3}{*}{$\begin{array}{c}\text { Lembaga } \\
\text { Pemasaran }\end{array}$} & \multicolumn{6}{|c|}{ Fungsi Pemasaran } \\
\hline & \multicolumn{2}{|c|}{ Pertukaran } & \multicolumn{2}{|c|}{ Pertukaran } & \multicolumn{2}{|c|}{ Pertukaran } \\
\hline & Beli & Jual & Simpan & Angkut & Standarisasi & Resiko \\
\hline \multicolumn{7}{|l|}{ Saluran 1} \\
\hline Tidak ada & $x$ & $x$ & $x$ & $x$ & $x$ & $x$ \\
\hline \multicolumn{7}{|l|}{ Saluran 2} \\
\hline Pengecer & $\mathrm{v}$ & v & $\mathrm{v}$ & v & v & $\mathrm{v}$ \\
\hline \multicolumn{7}{|l|}{ Saluran 3} \\
\hline Pengumpul & $v$ & v & $v$ & $v$ & $v$ & $v$ \\
\hline Pengecer & v & v & v & v & v & v \\
\hline
\end{tabular}

Sumber: Data Primer tahun 2019.

Fungsi fisik yang dilakukan oleh pengumpul dan pengecer ditunjukan dengan dilakukannya pengangkutan durian. Buah durian biasanya diangkut langsung oleh pengumpul dan pengecer, namun ada juga yang melibatkan tenaga kerja. Adanya fungsi pengangkutan oleh lembaga pemasaran secara tidak langsung telah membantu petani. Chaerani (2016) menjelaskan hal yang sama dengan adanya lembaga pemasaran yang melakukan pengangkutan dapat memberikan kemudahan bagi petani. Buah durian umumnya diangkut dengan menggunakan motor atau mobil, tergantung dari banyaknya jumlah durian yang akan diangkut. Fungsi fasilitas yang dilakukan oleh pengumpul dan pengecer adalah kegiatan penyortiran dan standarisasi. Pengumpul dan pengecer melakukan penyortiran dan standarisasi buah durian yang dibeli dikarenakan pembelian durian dengan sistem borongan dari petani tidak ada proses penyortiran dan standarisasi. Penyortiran dan standarisasi dilakukan agar diperoleh durian dengan kualitas yang baik, sehingga durian memiliki nilai jual yang tinggi dan dapat memperkecil resiko rusaknya buah durian yang akan dijual. Resiko yang ditanggung pengumpul tidak lebih besar dibandingkan pengecer, hal ini disebabkan buah durian yang berada pada pengumpul biasanya tidak terlalu lama dan akan angsung didistribusikan langsung ke pengecer.

Jumlah lembaga pemasaran yang ada di Desa Sidodadi lebih sedikit dibandingkan dengan petani. Kondisi ini menunjukan bahwasanya jumlah pembeli lebih sedikit dibandingkan dengan penjual, sehingga dapat dikatakan terjadinya pembentukan struktur pasar yang mengarah pada bentuk oligopsoni. Praktek penjual dan pembelian yang dilakukan lembaga pemasaran umumnya dilakukan dengan sistem borongan dan eceran. Penelitian yang dilakukan Wulandari et al. (2018) menunjukan hal yang sama bahwa praktek jual beli yang dilakukan lembaga pemasaran adalah sistem borongan dan eceran. Durian yang akan dibeli oleh pengumpul atau pengecer biasanya dilakukan dengan cara tawar menawar. Durian yang telah dibeli pengumpul atau pengecer biasanya dijual dalam bentuk buah segar, namun pengumpul atau pengecer di Desa Sidodadi memanfaatkan sisa durian yang rusak untuk diolah menjadi tempoyak yang dapat dijual atau dikonsumsi sendiri. 


\section{Margin dan Keuntungan Pemasaran}

Margin pemasaran menjadi salah satu indikator yang dapat digunakan dalam mengetahui efisiensi suatu pemasaran. Margin pemasaran terdiri dari biaya dan keuntungan pada sistem pemasaran Wulandari et al. (2018).

Tabel 2. Biaya Pemasaran

Table 2.Marketing Costs

\begin{tabular}{|c|c|c|c|c|}
\hline \multirow[t]{2}{*}{ Saluran } & \multicolumn{2}{|c|}{$\begin{array}{c}\text { Rincian Biaya Pemasaran Pengumpul } \\
\text { (Rp/Buah) }\end{array}$} & \multicolumn{2}{|c|}{$\begin{array}{l}\text { Rincian Biaya Pemasaran Pengecer } \\
\text { (Rp/Buah) }\end{array}$} \\
\hline & Tenaga Kerja & Transportasi & Tenaga Kerja & Transportasi \\
\hline 1 & - & - & - & - \\
\hline 2 & - & - & 700 & 200 \\
\hline 3 & 10 & 0 & 0 & 125 \\
\hline
\end{tabular}

Sumber: Data Primer tahun 2019.

Biaya pemasaran yang dikeluarkan oleh pengumpul dan pengecer meliputi biaya tenaga kerja dan transportasi untuk pengangkutan durian dari tempat penyedia durian, semakin besar biaya yang dikeluarkan akan berdampak pada besar atau kecilnya keuntungan. Selaras dengan Arbi et al. (2018) bahwa biaya pemasaran terdiri dari biaya transportasi dan tenaga kerja. Saluran 1 yang digunakan petani tidak mengeluarkan biaya pemasaran dikarenakan petani posisinya hanya menanggung biaya produksi. Pada saluran 2 , keterlibatan pengecer menunjukan adanya biaya pemasaran dikeluarkan untuk bantuan tenaga kerja dan transportasi pengangkutan durian. Saluran 3 pada pengumpul hanya mengeluarkan biaya untuk tenaga kerja dikarenakan biaya tranportasi telah masuk di dalam biaya tenaga kerja, sedangkan untuk pengecer mengalami hal yang sebaliknya, pengecer yang melakukan kegiatan pengangkutan tanpa menggunakan tenaga kerja dan pengecer hanya mengeluarkan biaya untuk transportasi. Biaya pemasaran menjadi komponen yang dibutuhkan dalam menghitung penyebaran margin pemasaran. Sebaran total biaya, keuntungan, dan total margin pemasaran dapat dilihat pada Tabel 3.

Tabel 3. Sebaran Total Biaya, Keuntungan, dan Total Margin Pemasaran Table 3. Distribution of Total Costs, Profits, and Total Marketing Margin

\begin{tabular}{crrrr}
\hline Saluran & $\begin{array}{c}\text { Harga Jual Petani } \\
\text { (Rp/Buah) }\end{array}$ & $\begin{array}{c}\text { Total Biaya } \\
\text { Pemasaran } \\
\text { (Rp/Buah) }\end{array}$ & $\begin{array}{c}\text { Total Keuntungan } \\
\text { (Rp/Buah) }\end{array}$ & $\begin{array}{c}\text { Total Margin } \\
\text { Pemasaran } \\
\text { (Rp/Buah) }\end{array}$ \\
\hline 1 & 17.000 & - & - & - \\
2 & 10.000 & 900 & 23.100 & 30.000 \\
3 & 10.600 & 135 & 26.265 & 29.900 \\
\hline
\end{tabular}

Sumber: Data Primer tahun 2019. 
Pada saluran 1, petani melakukan pemasaran durian langsung kepada konsumen akhir tanpa melibatkan lembaga pemasaran, sehingga untuk total margin pemasaran tidak ada. Saluran 2 menunjukan lembaga pemasaran yang terlibat dalam pemasaran adalah pengecer. Harga jual tinggi yang ditawarkan oleh pengecer menyebabkan besarnya total margin pemasaran di saluran 2. Baladina et al. (2011) menjelaskan bahwa tingginya harga jual berpengaruh dengan besarnya nilai margin pemasaran durian, sedangkan rendahnya nilai jual menyebabkan nilai margin pemasaran yang kecil. Saluran 3 melibatkan pengumpul didalamnya, sehingga menambah jumlah lembaga pemasaran yang terlibat. Harga jual relatif tinggi yang ditawarkan oleh pengumpul dan pengecer pada saluran 3 menyebabkan besarnya total margin pemasaran yang diperoleh, namun tidak lebih besar dibandingkan saluran 2 .

Total keuntungan tertinggi terjadi pada saluran 2 sebesar Rp 26.265,00/buah, sedangkan total keuntungan yang lebih rendah terjadi pada saluran 3 sebesar Rp 23.100,00/buah. Besarnya total biaya pemasaran yang ditanggung saluran 2 mengakibatkan adanya selisih total keuntungan yang diterima menjadi lebih rendah dibandingkan dengan saluran 3. Besarnya biaya pemasaran yang dikeluarkan setiap lembaga pemasaran tergantung dari fungsi pemasaran yang dilakukan (Putri et al. (2018). Penyebaran margin pemasaran tidak terlepas dengan adanya farmer share yang diterima oleh petani. Persentase farmer share yang diterima petani dapat dilihat pada Gambar 3.

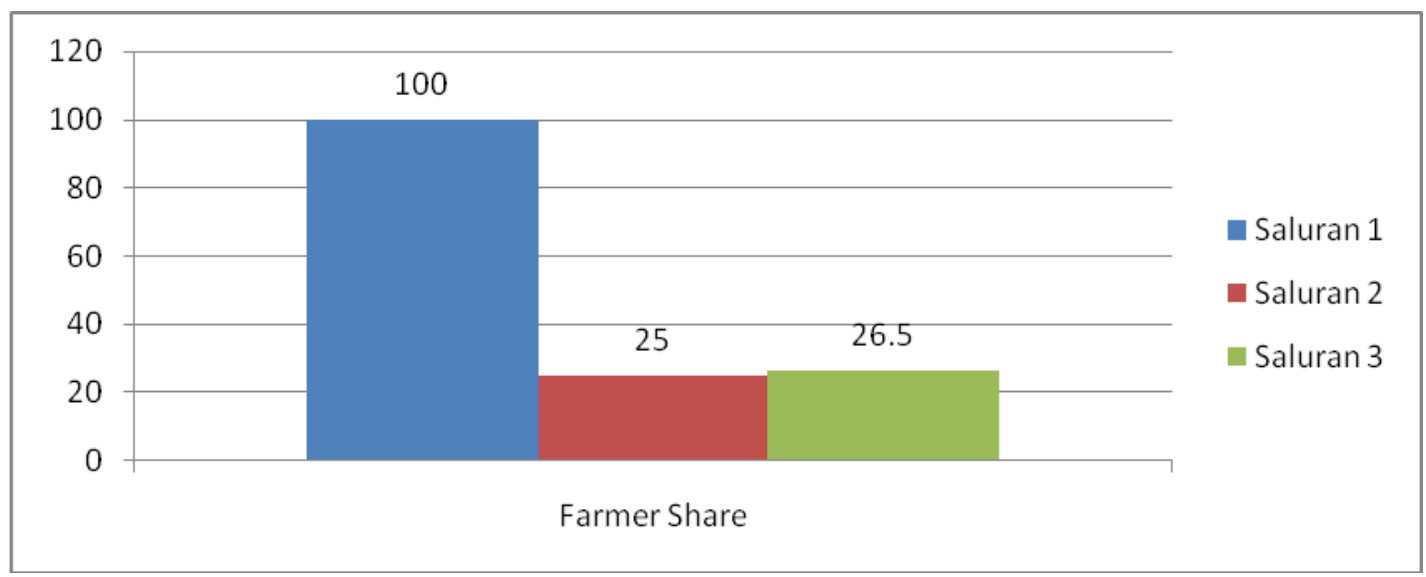

Gambar 3. Persentase farmer share

Figure 3. Farmer share persentation

Farmer share yang diterima oleh petani pada saluran 2 dan 3 masih sangat rendah dan belum merata. Besar kecilnya farmer share petani berdasarkan harga jual durian yang diterima dibandingkan dengan harga di konsumen akhir. Wulandari et al. (2018) menjelaskan rendahnya share yang diterima petani dikarenakan posisi petani hanya sebagi penerima harga. Pernyataan berbeda dinyatakan Arbi et al. (2018), besaran share petani ditentukan berdasarkan banyaknya pihak yang terlibat dalam pemasaran. Belum meratanya margin pemasaran, keuntungan, dan farmer share yang diterima petani dan mengarahnya struktur pasar pada bentuk oligopsoni menunjukan belum efisiennya pemasaran durian di Desa Sidodadi. Hal ini sesuai dengan pernyataan Arbi et al. (2018) bahwa efisiensi pemasaran dilihat dari margin pemasaran dan besaran nilai yang diterima petani dan lembaga pemasaran. 


\section{KESIMPULAN}

Saluran pemasaran durian di Desa Sidodadi mengarah pada bentuk pasar oligopsoni. Nilai margin pemasaran, keuntungan, dan share petani yang belum merata menyebabkan saluran pemasaran belum efisien.

\section{DAFTAR PUSTAKA}

Annisa, I., Asmarantaka, R. W. dan Nurmalina, R. (2018). Efisiensi pemasaran bawang merah (Kasus: Kabupaten Brebes Provinsi Jawa Tengah). Jurnal Ilmiah Manajemen. 8(2), 254271.

Arbi, M., Thirtawati. dan Junaidi, Y. (2018). Analisis saluran dan tingkat efisiensi pemasaran beras semi organik di Kecamatan Rambutan Kabupaten Banyuasin. Jurnal SEP. 11(1), 22-32.

Baladina, N., Anindita, R. dan Ariani, R.P. (2011). Analisis efisiensi pemasaran durian di Desa Wonoagung, Kecamatan Kasembon, Kabupaten Malang. Jurnal Habitat. 22(1), 1-11.

Chaerani, D, S. (2016). Margin dan efisiensi pemasaran kopra di Desa Simalegi Kecamatan Siberut Barat Kabupaten Kepulauan Mentawai. Jurnal Bibiet. 1(2), 81-94.

Hanum, I.M., Qurniati, R., dan Herwanti, S. (2018). Peran wanita pedesaan hutan dalam peningkatan pendapatan rumah tangga. Jurnal Sylva Lestari. 6(3), 36-45.

Kholifah, U.N., Wulandari, C., Santoso, T. dan Kaskoyo, H. (2017). Kontribusi agroforestri terhadap pendapatan petani di Kelurahan Sumber Agung Kecamatan Kemiling Kota Bandar Lampung. Jurnal Sylva Lestari, 5(3), 39-47.

Kristin, Y., Qurniati, R. dan Kaskoyo, H. (2018). Interaksi masyarakat hutan terhadap pemanfatan lahan Taman Hutan Raya Wan Abdul Rachman. Jurnal Sylva Lestari. 6(3), 18.

Olivi, R., Qurniati, R. dan Firdasari. (2013). Kontribusi agroforestri terhadap pendapatan petani di Desa Sukaharjo 1 Kecamatan Sukoharjo Kabupaten Pringsewu. Jurnal Sylva Lestari. 3(2), 1-12.

Putri, R.K., Nurmalina. R. dan Burhanudin. (2018). Analisis efisiensi dan faktor yang mempengaruhi pilihan saluran pemasaran. Jurnal IImiah dan Manajemen. 8(1), 109135.Sabrina, Winandi, R., Rachmania, D. 2013. Pemasaran durian di Pasar Induk Kramat Jati. Jurnal Forum Agribisnis, 3(2). 187-200.

Qurniati R., Febryano I.G., and Zulfiani D. 2017. How Trust Influence Social Capital to Support Collective Action in Agroforestry Development. Biodiversitas. 18(3), 1201-1206.

Suminartika, E. dan Djuanalia, I. (2017). Efisiensi pemasaran beras di Kabupaten Ciamis Dan Jawa Barat. Jurnal Pemikiran Masyarakat IImiah Berwawasan Agribisnis. 3(1), 13-28. 
Syofiandi, R.R., Hilmanto, R. dan Herwanti, S. (2016). Analisis pendapatan dan kesejahteraan petani agroforestri di Kelurahan Sumber Agung Kecamatan Kemiling Kota Bandar Lampung. Jurnal Sylva Lestari. 4(2), 17-26.

Unit Pelaksana Teknis Daerah Tahura WAR. (2017). Blok Pengelola Tahura Wan Abdul Rachman. Bandar Lampung: Informasi Tahura WAR.

Wanderi, Qurniati, R. dan Kaskoyo, H. (2018). Kontribusi tanaman agroforestri terhadap pendapatan dan kesejahteraan petani. Jurnal Sylva Lestari. 7(1), 118-127.

Winarni, S., Yuwono, S.B. dan Herwanti, S. (2016). Struktur pendapatan, tingkat kesejahteraan dan faktor produksi agroforestri kopi pada Kesatuan Pengelolaan Hutan Lindung Batu Tegi. Jurnal Sylva Lestari. 4(1), 1-10.

Wulandari, D., Qurniati, R., dan Herwanti, S. (2018). Efisiensi pemasaran durian (Durio zibethinus) di Desa Wisata Durian Kelurahan Sumber Agung. Jurnal Sylva Lestari. 6(2), 68-76. 